
\title{
$\begin{array}{ll}\text { Research Square } & \begin{array}{l}\text { They should not be considered conclusive, used to inform clinical practice, } \\ \text { or referenced by the media as validated information. }\end{array}\end{array}$
}

\section{Dynamic Changes in Quality of Life, Psychological Status, and Body Image in Women With Different Types of Breast Cancer Surgery: 8-year Follow Up}

Sriyani padmalatha K.M

National Cheng Kung University College of Medicine

Yi-Lin Wu

National Cheng Kung University Hospital

Shikha Kukreti

National Cheng Kung University College of Medicine

Chang-Chun Chen

National Cheng Kung University College of Medicine

Chia-Ni Lin

National Cheng Kung University College of Medicine

Yi-Tseng Tsai

National Cheng Kung University College of Medicine

Han-Chang Ku

National Cheng Kung University College of Medicine

Su-Ying Fang

National Cheng Kung University College of Medicine

Jung-Der Wang

National Cheng Kung University College of Medicine

Nai-Ying Ko ( $\square$ ko.naiying@gmail.com )

National Cheng Kung University College of Medicine https://orcid.org/0000-0002-3007-2537

\section{Research Article}

Keywords: breast cancer survivors, Quality of life, body image, psychological status, mastectomy, modified radical mastectomy, breast reconstructions

Posted Date: January 3rd, 2022

DOI: https://doi.org/10.21203/rs.3.rs-1115792/v1

License: (9) (7) This work is licensed under a Creative Commons Attribution 4.0 International License. Read Full License 


\section{Abstract}

Purpose

To explore the dynamic changes in Quality of Life (QoL), anxiety/depression status, and body image (BI) of women who received different types of breast cancer (BC) surgery within an 8-years follow-up period.

Methods

Women with major BC surgeries were invited to complete the World Health Organization Quality of Life-Brief (WHOQOL-BREF), the European quality of life five dimensions questionnaire (EQ-5D), and a body image scale within 8 years of surgery. Kernel smoothing methods were applied to describe dynamic changes in QoL, anxiety/depression, and $\mathrm{BI}$ at different time points. Linear mixed effects models were constructed to identify the interaction between time, different types of surgery, and the determinants of QoL in these patients.

Results

A total of 1,803 women who had undergone a mastectomy, a modified radical mastectomy (MRM), and breast reconstruction (BR) were included. The BR group exhibited a high QoL score of WHOQOL one to five years after surgery with some fluctuations. The MRM group had comparatively stable, low QoL scores of WHOQOL items and less depressed/anxious. BR group generally showed fluctuated, lower scores of BI two years after operation, but they exhibited more anxiety/depression status after five years. Medical comorbidities, the status of anxiety/depression, and BI were the major factors influencing all domains and items of the WHOQOL BREF.

Conclusion

While MRM may decrease the likelihood of depression in patients with BC and BR would significantly improve their QoL in the first 5 years. We recommend that these findings should be considered and discussed in the patient participatory decision-making for breast surgery.

\section{Introduction}

Breast cancer (BC) is the most common cancer in women globally, despite significant investments, research, and new treatments[36, 57, 59]. In Taiwan, BC is the highest type of cancer cases among Taiwanese women. It is the fourth leading cause of cancer death in Taiwan[65, 66]. According to the cancer treatment guidelines, the most common BC surgical interventions include different type of mastectomies (total/simple mastectomy, modified radical mastectomy (MRM)) and breast reconstruction (BR) [4, 22, 44, 57]. However, women who undergo a mastectomy or an MRM will likely have BR, either with saline or silicone implants, tissue from another part of the body, or a combination of the two after a consensus between the patient and breast surgeon/plastic surgeon [14, 27 , $52,57]$.

Improvements in early detection and treatment of BC with the absence of metastasis have led to a five yearsa survival rate $89 \%$ globally, and the life expectancy of BC survivors has increased to nearly 23 years $[8,66]$. Therefore, important health outcomes such as Quality of life (QoL) are a concern at the first clinical consultation to maintain long time sustainable healthy outcomes among BC survivors $[7,8,21,41,65]$.

QoL in BC survivors is a major health outcome measure that should be started at the first clinical encounter [43]. According to previous studies, surgical decisions and methods of surgery highly influence QoL among these patients. For example, mastectomy or MRM affect women's body image and percpetions of physical esthetics. However, previous studies were conducted after a short term follow-up [12, 41, 56, 62]. Progression of BC treatments, including various breast surgeries, removal of lymph nodes, chemotherapy, and radiotherapy, or a combination of these treatments, may greatly influence QoL, anxiety/depression, and BI due to enormous changes in activities of daily life and societal interaction over the timeline [5, 18, 40, 71]. Therefore, awareness of the long terms health effects of such treatments is important for policymakers to develop a proactive, long-term perspective of health care strategies [15, 46].

In addition, BC surgeries and anxiety/depression have a significant relationship, and it appears that women undergoing mastectomy or MRM alone are more vulnerable than their BR counterparts due to the removal of the breast, which plays a significant role in the female BI (e.g., a sense of being less female, reduced sense of attractiveness to a partner, and lowered levels of confidence) $[3,17,19,48]$.

This study is a comprehensive analysis intended to show the long-term health effects of mastectomy and MRM compared with BR across the lifetime using real-life data because few studies have been conducted examining the dynamic changes in QoL, psychological status, and BI in women who have undergone BR compared with different types of mastectomies alone. Such studies have generally had examined short-term follow-up in Asian populations as well as globally $[25,33,65,67]$. The results of this study will help healthcare teams update and determine when and how to improve QoL among women with different types of mastectomies and BR since the choice of surgical treatment heavily influences these patients' long-term QoL, psychological status, and BI [8, 41, 51 , 65]. Therefore, the aim of this study is to describe and compare the dynamic changes in QoL, psychological status, and $\mathrm{BI}$ of women who have undergone BC surgery along with identifying the interaction between different time points, various types of BC surgery, and the determinants of QoL within an 8-year followup period.

\section{Materials And Methods}

This study has begun after approval from the Institutional Review Board (IRB) of the National Cheng Kung University Hospital (review No: B-ER-110-050). Every patient has submitted an informed consent form. 


\section{Study population}

This is a longitudinal cohort study with repeated measurement of QoL and BI using the Cancer Center Database (CCBD) of the National Cheng Kung University Hospital (NCKUH) in Taiwan. This study included pathologically verified women with BC who were diagnosed from January 2010 where follow-up was continued until April 2021. Inclusion criteria were as follows: women with BC who had undergone total/simple mastectomy, MRM, or BR, age above 18 years old, breast cancer with ICD-0-3(International Classification of Diseases - Oncology, 3rd edition) and a pathological stage of 0-3, according to the American Joint Committee on Cancer Staging Manual (7th edition) who were still within 10 years after surgery. Breast conservative surgery (BCS) (lumpectomy, quadrantectomy, partial mastectomy, or segmental mastectomy), those with recurrent cancer, bilateral breast cancer surgeries, or who were unable to read or answer questions were excluded. All eligible candidates who came to the Cancer Center at NCKUH for regular follow-up were encoded into the final data analysis (supplementary figure 1). At each visit, the NCKUH Cancer Center asked them to voluntarily fill out the QoL questionnaire and the Body Image Scale (BIS). An experienced research assistant was available to provide instructions, clarify the meaning of the items, or answer any questions from the participants using a standardized method and assistance to self-complete the Taiwan version of the WHOQOL-BREF, the EQ-5D questionnaire, and BIS via tablet computers. Demographic and clinical data for the participants were obtained from electronic medical records and NCKUH's cancer registry.

\section{Instruments}

The World Health Organization Quality-of-Life-Brief (WHOQOL-BREF) is a standard QoL questionnaire, which was established under the guidance of the WHO $[23,24]$. It has been verified to have proper psychometric properties. The Taiwan version of the WHOQOL-BREF was used. It comprises a total of 28 items, including physical, psychological, social, and environmental domains and two local items (being respected/accepted and eating/food) [65, 69] and validated to have good internal consistency reliability (Cronbach's $\alpha>0.91$ ), test - retest reliability (correlation coefficient $>0.75$ ) and construct validity in patients with malignancies $[38,69,70]$. All items were measured on a 5-point Likert scale, where a higher score indicates a better quality of life. The average score of all the items in the same domain was multiplied by 20 to calculate the domain score. Then, the score for each domain ranged from 0 to 100 . If there were missing items in the same domain, then the domain scores were calculated using the average scores in the same domain. However, if more than two items were missing, since there were so few items in the domain, the mean domain score was not calculated but for social domain, if one items was missing then mean domain score did not calculate [31, 67].

The anxiety/depression status among patients who had undergone breast surgery was measured using the anxiety/depression domain from the European Quality of Life Five Dimensions Questionnaire (EQ-5D) because no data from valid questionnaires were available in the NCKUH database. The EQ-5D questionnaire is a universal, preference-based tool suitable for decision analysis [50,60]. The EQ-5D questionnaire assesses five dimensions of QoL: mobility, self-care, usual activities, pain or discomfort, and anxiety/depression, where each item has three levels of severity (no problems at all, some/moderate problems, and severe/extreme problems) $[9,35]$.

The Body Image Scale (BIS) has been validated to measure discomfort related to BI women with breast cancer [19, 28]. The BIS has ten items covering three concepts: affective, behavioral, and cognitive symptoms of body image. Each item in the scale has 4 responses ( 0 - not at all, 1 - a little, 2 - quite a bit, and 3 very much), where the total score ranges from 0 to 30 , and a total score higher indicates have high distress levels related to BI after cancer treatments or surgeries. The Taiwan version of the BIS has been shown to have good internal consistency (Cronbach's $a=0.90)$ for breast cancer [19, 58].

\section{QoL function after major breast cancer surgeries.}

Mastectomy, MRM, and BR are the major BC surgical approaches for women with BC. For each QoL assessment, the time point was defined as the period between the date of surgery and the QoL assessment date. The kernel-smoothing method was applied to the analysis of the QoL functions in terms of time after surgery $[31,68]$. Specifically, a detailed time point per year and the mean QoL estimation at this time point were used to extract the average of the QoL calculations, where the weights were identified using a bandwidth parameter. The bandwidth was set as 0.5 for this study. A bootstrap approach was used to construct the relevant confidence intervals $(\mathrm{Cl})$ for the mean function of the QoL estimations. The subject's units applied for bootstrapping rather than the assessment. At each time point, a 95\% Cl was constructed based on the 2.5 and 97.5 percentiles of 1,000 estimations of the mean QoL functions using bootstrapping [68]

\section{Confounding factors for dynamic changes of QoL in women with major breast cancer surgeries.}

For this study, age, marital status, education levels, family income, co-morbidities, pathological stage, type of lymph node dissection, sentinel lymph node biopsy, time since chemotherapy, radiotherapy, hormone therapy, and interactions among types of surgeries (mastectomy, MRM, and BR) were considered as a possible confounding factors according to previous literature $[33,65,67]$. Age was continuously calculated at each QoL assessment. Usually, in the initial stage of treatments or diagnosis, the clinician records education level, income, marital status, comorbidities, height, and weight for future reference and continuous follow up. The status of further treatments such as chemotherapy, radiotherapy, and hormone therapy are encrypted according to frequency of occurrence, such as before surgery, in between surgeries, or after surgery. Medical comorbidities are included based on patient medical records, and include cerebrovascular disease, coronary artery disease, chronic obstructive pulmonary disease (COPD), diabetes mellitus, and end-stage renal disease [1, 45]. In the present study, the above-mentioned confounders were automatically entered [37,68]. Furthermore, the state of metastasis at the time of the QoL assessment was observed by referencing medical records and radiological reports. Disease progression at the time of the QoL assessment was based on pathologic/radiographic evidence and followed institutional guidelines[67].

\section{Statistical Analysis}

A kernel-type smoother was applied to demonstrate the dynamic changes in the item scores, domain scores, and total scores for the Taiwan version of the WHOQOL-BREF, the EQ5D anxiety/depression items, and the total BIS score $[33,65,68]$ using STATA version 17.0 software. Groups comprising various 
pairings of mastectomy, MRM, and BR were used to compare the trends in QoL, anxiety/depression, and BI changes over time. The timeline of dynamic changes depicted one year time points until 8 years after undergoing BC surgery, but the number of participants decreased during the time. A multiple linear regression mixed effect model was constructed to identify the interaction between the different time points (e.g., prior to one year after surgery and more than five years after surgery) and surgery type to identify the factors affecting QoL using repeated assessments of each item and the domain of the WHOQOL-BREF questionnaire within individual subjects after controlling for the possible confounding factors mentioned above [34, 64, 65]. A negative coefficient stated that the variable prediction is a poor QoL score as a magnitude representing the effect. Statistical Analysis System software version 9.4 (SAS Institute, Cary, NC, USA) was used to conduct the analyses. Two-sided $p$-values were applied.

\section{Results}

\section{Clinical and demographic characteristics in women with breast cancer surgeries.}

A total of 1,803 women with $\mathrm{BC}$ who had undergone surgical interventions (Total/simple mastectomy $=28 \%, \mathrm{MRM}=66 \%$, and $\mathrm{BR}=6 \%$ ) participated in the study and were continuously followed up by measuring the QoL and BI repeatedly from 2017 to 2021 . The mean age (44.23) of the BR group was relatively low compared with women who had undergone a mastectomy and MRM. Most patients undergoing a mastectomy and BR were in pathologic stage I. However, a significantly higher proportion of patients in stages II and III had undergone MRM alone. $72.24 \%$ in the mastectomy group received a sentinel lymph node biopsy while $99.79 \%$ of the MRM patients had undergone axillary lymph node dissection. No one in the BR group was performed a regional lymph node dissection. Most of the women with breast surgeries received chemotherapy for less than 6 months, and radiotherapy and hormonotherapy for less than one year. During the follow-up period, 265 deaths occurred in the three groups, and most of them died 5 years post-surgery. Nevertheless, there were no other significant differences in the demographic and clinical characteristics among groups. The total mean BIS score, mean score of the health status determine from the EQ5D scale, and mean QoL of WHOQOL-BREF score were compared for the three groups (Table 1). 
Table 1

Demographic and clinical characteristics and type of surgery among women with breast cancer

\begin{tabular}{|c|c|c|c|c|c|c|}
\hline & Total(n) & Mastectomy(M) & MRM & BR & $p$ & $\begin{array}{l}\text { Post hoc group } \\
\text { comparison }\end{array}$ \\
\hline Total no. of patients & 1803 & 508 & 1181 & 114 & & \\
\hline Age (year); Mean \pm SD. & 1803 & $53.51 \pm 10.31$ & $54.05 \pm 12.01$ & $44.23 \pm 9.39$ & $<0.0001$ & $M R M>B R, M>B R$ \\
\hline$\leq 55$ & 1091 & $309(60.8 \%)$ & $684(57.9 \%)$ & $98(85.9 \%)$ & \multirow[t]{3}{*}{$<0.0001$} & \multirow[t]{3}{*}{$M R M>B R, M>B R$} \\
\hline 56 to 64 & 394 & $120(23.6 \%)$ & $262(23.6 \%)$ & $12(10.5 \%)$ & & \\
\hline$\geq 65$ & 318 & $79(15.5 \%)$ & $235(19.9 \%)$ & $4(3.51 \%)$ & & \\
\hline Education $\leq 6$ years & 44 & $10(11.2 \%)$ & $33(17.6 \%)$ & $1(2.94 \%)$ & \multirow[t]{3}{*}{0.0005} & \multirow[t]{3}{*}{$\mathrm{MRM}>\mathrm{BR}, \mathrm{M}>\mathrm{MRM}$} \\
\hline $7-12$ years & 144 & $38(42.7 \%)$ & $94(50.3 \%)$ & $12(35.2 \%)$ & & \\
\hline$>12$ years & 121 & $41(46.1 \%)$ & $59(31.5 \%)$ & $21(61.7 \%)$ & & \\
\hline Married or cohabitating & 265 & $76(85.2 \%)$ & $162(86.6 \%)$ & $27(79.4 \%)$ & 0.44 & \\
\hline In come family <US\$1803.78/month & 127 & $30(33.7 \%)$ & $81(43.3 \%)$ & $16(47.1 \%)$ & 0.18 & \\
\hline Comorbidity (+) & 99 & $32(35.9 \%)$ & $62(33.1 \%)$ & $5(14.7 \%)$ & 0.06 & \\
\hline Anxiety/Depression (+) & 164 & $40(20.9 \%)$ & $105(26.1 \%)$ & $19(25.0 \%)$ & 0.39 & \\
\hline $\mathrm{BMI} \geq 27$ & 309 & $84(19.9 \%)$ & $212(23.2 \%)$ & $13(12.4 \%)$ & 0.02 & $\mathrm{MRM}>\mathrm{BR}$ \\
\hline Breast side (right side) & 889 & $240(47.2 \%)$ & $581(49.2 \%)$ & $68(59.6 \%)$ & 0.06 & $M<M R M$ \\
\hline Pathologic stage 0 & 227 & $175(34.5 \%)$ & $25(2.15 \%)$ & $29(25.6 \%)$ & \multirow{6}{*}{$\begin{array}{l}<.0001 \\
0.00\end{array}$} & \multirow[t]{6}{*}{$M>M R M>B R$} \\
\hline 1 & 516 & $220(43.3 \%)$ & $248(21.3 \%)$ & $48(42.5 \%)$ & & \\
\hline 2 & 656 & $106(20.9 \%)$ & $528(45.3 \%)$ & $22(19.5 \%)$ & & \\
\hline 3 & 308 & $2(0.39 \%)$ & $295(25.3 \%)$ & $11(9.73 \%)$ & & \\
\hline 4 & 66 & $1(0.02 \%)$ & $62(5.25 \%)$ & $3(2.63 \%)$ & & \\
\hline Missing & 30 & & & & & \\
\hline Sentinel lymph node biopsy (+) & 530 & $367(72.2 \%)$ & $114(9.65 \%)$ & $49(42.9 \%)$ & $<0.0001$ & $\mathrm{M}>\mathrm{MRM}>\mathrm{BR}$ \\
\hline Axillary lymph node dissection (+) & 1259 & $56(11.1 \%)$ & $1150(97.8 \%)$ & $53(46.9 \%)$ & $<0.0001$ & $\mathrm{M}<\mathrm{MRM}$ \\
\hline Regional lymph nodes dissection (+) & 22 & $1(0.20 \%)$ & $21(1.79 \%)$ & 0 & & \\
\hline Chemotherapy: Never & 797 & $364(71.6 \%)$ & $367(31.1 \%)$ & $66(57.9 \%)$ & $<0.0001$ & $M>M R M>B R$ \\
\hline after diagnosis $\leq 6$ months & 1004 & $144(28.3 \%)$ & $812(68.7 \%)$ & $48(42.1 \%)$ & & \\
\hline after diagnosis $>6$ months & 2 & 0 & $2(0.17 \%)$ & 0 & & \\
\hline Radiotherapy: Never & 1232 & $492(96.8 \%)$ & $646(54.7 \%)$ & $94(82.5 \%)$ & $<0.0001$ & $\mathrm{M}>\mathrm{MRM}>\mathrm{BR}$ \\
\hline after diagnosis $\leq$ one year & 562 & $14(2.76 \%)$ & $529(44.8 \%)$ & $19(16.6 \%)$ & & \\
\hline after diagnosis >one year & 9 & $2(0.39 \%)$ & $6(0.51 \%)$ & $1(0.88 \%)$ & & \\
\hline Hormone therapy: Never & 691 & $258(50.8 \%)$ & $385(32.6 \%)$ & $48(42.1 \%)$ & $<0.0001$ & $\mathrm{MRM}>\mathrm{M}$ \\
\hline after diagnosis $\leq$ one years & 1108 & $250(49.2 \%)$ & $792(67.1 \%)$ & $66(57.9 \%)$ & & \\
\hline after diagnosis >one year & 4 & 0 & $4(0.34 \%)$ & 0 & & \\
\hline
\end{tabular}

$M=$ Mastectomy, MRM= modified radical mastectomy, BR= breast reconstruction significant group in the post hoc test (Tukey's Studentized Range Test for type I error/ Scheffe's post hoc test for type II error) SD - standard deviation, WHOQOL -World Health Organization Quality of Life Scale, EQ5D -Euro QOL Five Dimensions Scale 


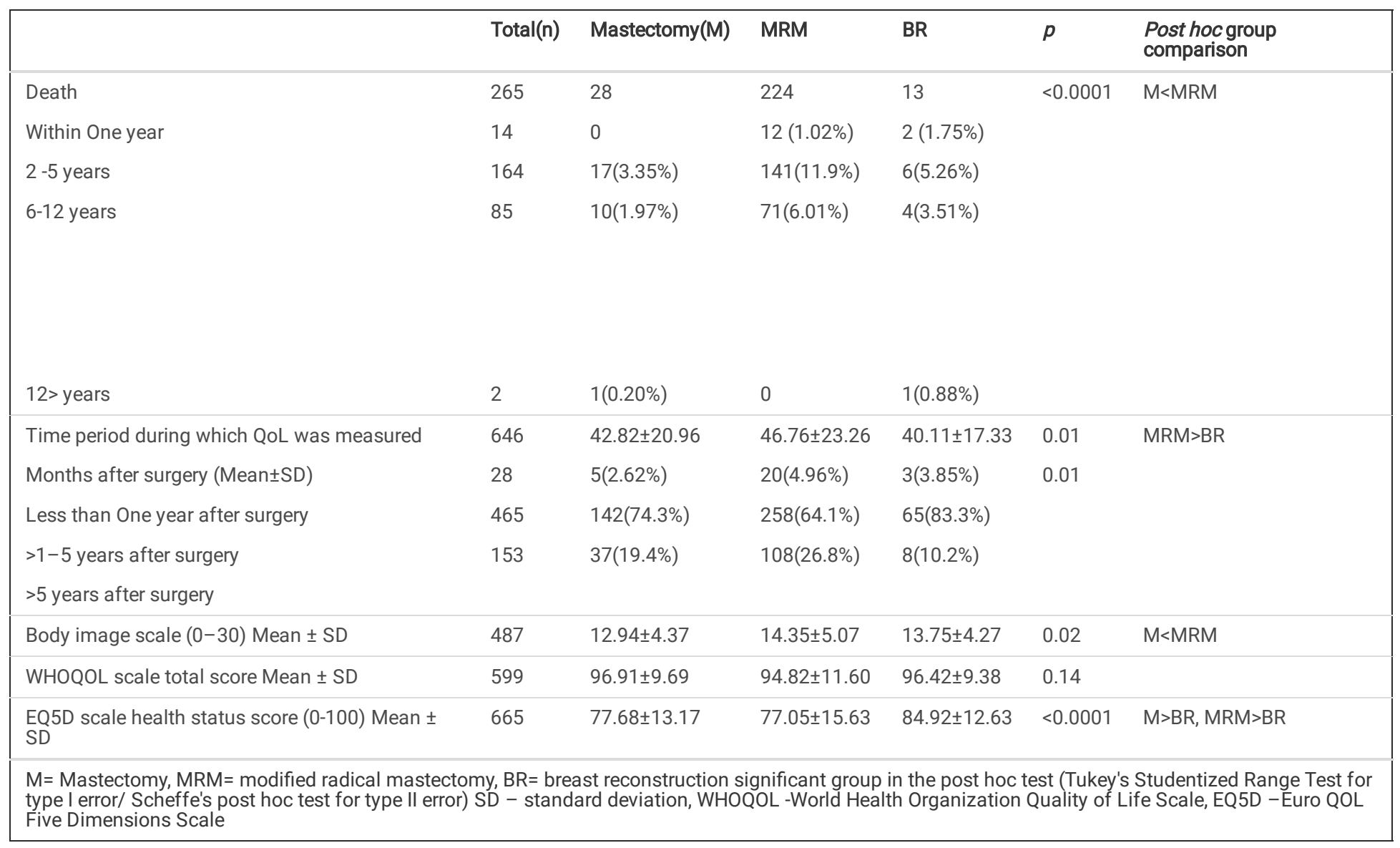

\section{Dynamic changes in QOL in women with BC after surgery}

Figure 1 demonstrates variations in QoL scores on four domains and some selected items of WHOQOL BREF. The MRM group appeared to be stable with a low QoL score over time in the psychological domain, although the mastectomy and BR groups revealed relatively high QoL status for one to two years, after which the same fluctuations occurred although the QoL status remained high. In the physical, social, and environmental domain, all groups showed a substantial variance in QoL until six years, after which the BR and mastectomy groups had lower QoL scores compared with the MRM group. Also, we noticed that the BR sample was significantly smaller five years post-surgery and beyond. (Figure 1). Up to five years post-surgery, the three groups had a similar trend in the general QoL status. The BR group had a wider $95 \% \mathrm{Cl}$ with a quite low general QoL score after five years compared with the mastectomy and MRM groups. Also, we noticed that the BR sample was significantly smaller five years post-surgery and beyond. The mastectomy group exhibited significantly high QoL from 7 to 8 years post-surgery during the follow-up; however, the MRM group exhibited a significantly poor QoL status after 7.5 years. Over time, the BR group had significant fluctuations in the following items: "positive feelings," "body image and appearance," "eating/food (added for Taiwan)," "being respected (added for Taiwan)," "activities of daily living" and "dependence on medical substances" with a drop in the QoL scores as compared to the mastectomy and MRM groups. The MRM group exhibited a stable trend with a low QoL score during the follow-up period. Both the MRM and BR groups exhibited slightly high variability on items of "pain and discomfort" compared with the mastectomy group at time point zero to 1.5 years, but after that, the three groups exhibited a similar QoL status (figure 1)

The results for the anxiety and depression status appeared to be quite different from those obtained for the psychological domain, where the BR group had high anxiety and depression scores with massive fluctuations from 6 to 8 years, followed by the mastectomy group and the MRM group, which exhibited a stable trend with lowering of anxiety and depression during the follow-up, in that order and the BR group had a wider $95 \% \mathrm{Cl}$ after five years compared with the mastectomy and MRM groups because of small sample size in BR group (figure2). Although, there seem no significant differences on the proportions of patients with severe depression among the three groups (the supplementary Table 1). This finding corroborates the results shown in Figure 2, because a high domain score indicates a higher likelihood of depression/anxiety in EQ5D. The BR group had better BI status at the time of surgery, but after one and a half years, this group exhibited the least satisfactory BI throughout the follow-up period. The mastectomy group had a better BI compared with the MRM and BR groups. However, the MRM group showed a stable trend with satisfaction with BI scores between those of the mastectomy and BR groups and they seemed to be less depressed/anxious throughout of follow up (Figure 2).

\section{QOL in different timeline after breast cancer surgeries}

In this study, a comparison was made between major BC surgeries at different time points after surgery based on mixed effects analyses in all domains and QOL items and anxiety and depression after control of confounders (Table 2). As compared with the mastectomy group with MRM, the results showed that the MRM group had a lower QoL score items related to self-esteem and sexual activities in the first year of surgery. Also, the MRM group had poor QoL in terms of pain five years after surgery compared with the mastectomy group. The BR group had a significantly high anxiety and depression status and poor QoL in the 
physical domain on some items and on the item "being respected" added for Taiwan less than one year of surgery compared with the mastectomy group. Similarly, five years after surgery, the BR group had a high anxiety and depression status and low QoL status in the physical, social, and environmental domains and some of the items in the other four domains as compared with the mastectomy group. When compared with the MRM and BR groups, the MRM group exhibited poor QoL status in items measuring pain one year after surgery as compared with the BR group. Similarly, the BR group appeared to have poor QoL in the social and environmental domains and in some items in each domain five years after surgery compared with the MRM group. However, the comparisons demonstrated that the BR group has better QoL between one and five years after surgery (Table 2). 
Table 2

Regression coefficients for interaction between major breast cancer surgeries and different time point after surgery based on Multiple Linear Regression analyses (mixed effects models) of the WHOQOL-BREF and EQ5D scale (statistical significance only where shown $(p<0.05)$ )

\begin{tabular}{|c|c|c|c|c|c|c|c|c|c|}
\hline SURGERIES & \multicolumn{3}{|c|}{ Mastectomy (Ref.) vs MRM } & \multicolumn{3}{|c|}{ Mastectomy (Ref.) vs BR } & \multicolumn{3}{|c|}{ MRM (Ref.) vs BR } \\
\hline $\begin{array}{l}\text { TIME POINT } \\
\text { ITEMS SCORE }\end{array}$ & $\begin{array}{l}\text { after } \\
\text { surgery } \leq \\
1 \text { Year }\end{array}$ & $\begin{array}{l}\text { after } \\
\text { surgery } 1 \\
\text { to } 5 \text { Year } \\
\text { (Ref.) }\end{array}$ & $\begin{array}{l}\text { after } \\
\text { surgery }>5 \\
\text { Year }\end{array}$ & $\begin{array}{l}\text { after surgery } \\
\leq 1 \text { Year }\end{array}$ & $\begin{array}{l}\text { after } \\
\text { surgery } 1 \\
\text { to } 5 \text { Year } \\
\text { (Ref.) }\end{array}$ & $\begin{array}{l}\text { after surgery } \\
>5 \text { Year }\end{array}$ & $\begin{array}{l}\text { after } \\
\text { surgery } \leq 1 \\
\text { Year }\end{array}$ & $\begin{array}{l}\text { after } \\
\text { surgery } \\
1 \text { to } 5 \\
\text { Year } \\
\text { (Ref.) }\end{array}$ & $\begin{array}{l}\text { after surgery } \\
>5 \text { Year }\end{array}$ \\
\hline
\end{tabular}

$\begin{array}{lll}\text { Anxiety/Depression } & 0.66(0.30)^{*} & 0.57(0.16)^{2}\end{array}$

\section{WHOQOL BREF}

General QoL

\begin{tabular}{llll}
\hline physical domain & $-19.54(9.61)^{*}$ & $-10.41(5.41)^{*}$ & $2.06(0.64)^{2}$ \\
\hline Pain & $-0.62(0.21)^{2}$ & $2.31(0.65)^{2}$ & $0.82(0.42)^{*}$ \\
$\begin{array}{l}\text { Medical } \\
\text { dependency }\end{array}$ & & $-1.51(0.59)^{*}$ \\
\hline Mobility & $-1.05(0.49)^{*}$ & $-0.86(0.39)^{*}$ & \\
\hline Sleep and rest & & $-0.79(0.49)^{*}$ &
\end{tabular}

Psychological

domain

Positive feelings

$-0.70(0.37) *$

Thinking

$-0.68(0.33)$ *

Self-esteem $\quad \quad \quad * 1.01(0.47)$

Social domain

$-23.67(4.92)^{1}$

$-18.23(5.55)^{2}$

Personal

relationships

$-0.72(0.24)^{2}$

Sexual activity

$-1.13(0.51)$

$-1.45(0.36)^{1}$

$-1.26(0.34)^{2}$

Social support

$-0.81(0.36)$ *

$-0.60(0.20)^{2}$

Being respected

(SDTW)

$-19.82(4.54)^{1}$

$-16.33(5.23)^{2}$

Environment

$-14.28(4$.

$-13.33(5.31)^{*}$

domain

52) ${ }^{2}$

Physical

$-0.83(0.38)$ *

$-0.96(0.34)^{2}$

environment

$-0.78(0.37)$ *

$-0.74(0.37)$ *

Opportunities

$-1.38(0.51)^{2}$

Home environment

$-0.96(0.24)^{1}$

$-0.53(0.25)$ *

Access quality care

$-0.65(0.24)^{2}$

$-0.54(0.25)$ *

Eating/food

(EDTW)

$-13.73(4.53)^{2}$

$-12.92(5.33)$ *

Significant showing as a $p^{*}<0.05,{ }^{1}=<0.001,{ }^{2}=<0.01$ and standard errors value under parentheses. All models were controlled for the following confounders: age group ( $>55 /<55$ years old), marital status (yes/no), Education levels $(\geqslant 12 /<12$ years), family income $(>/<1803.78 /$ month) co-morbidities, pathological stage, type of lymph node dissection (sentinel lymph node biopsy $(+/-)$ axillary lymph node dissection $(+/-)$ ), time after chemotherapy $(>6 /<6$ months), time after radiotherapy (<one year), hormone therapy $(>/<$ one year), and interactions among type of surgery (mastectomy, modified radical mastectomy(MRM and breast reconstruction(BR)) WHOQOL-BREF - World Health Organization Quality of Life Questionnaire, EQ5D- Euro QOL Five

Dimensions Questionnaire, SDTW- items added in the social domain specific to Taiwan, EDTW-items added in the environmental domain specific to Taiwan

\section{Factors determining on QOL among women undergoing major breast cancer surgery}

Multiple linear regression mixed models were performed to identify factor affecting the QOL among patients undergoing mastectomies, MRM, and BR. Lymph node dissection was associated with a lower score in the physical domain of the QoL. In addition, marital status was correlated with higher scores of many items in the psychological domain of the QoL. Education level, radiotherapy less than one year and a positive sentinel lymph node biopsy were negatively 
associated with the social domain in QoL. On the other hand, lower scores in many items of the environment domain were associated with married women who had a lymph node dissection and a sentinel lymph node biopsy. Women receiving hormone therapy within less than one-year post-surgery were positively associated with the item score related to sexual activity. Finally, we found that medical comorbidities, anxiety/depression status, and body image were the major factors influencing general QoL and almost all domains and items of the WHOQOL BREF. After controlled confounding, it was found that the MRM group had a significantly low QoL score for the energy \& fatigue, mobility, work capacity, spirituality, self-esteem, and personal relationships items compared with the mastectomy group. Furthermore, the BR group had a positive relationship with items of mobility as compared with MRM. However, we did not find any statistically significant association in scores of each item or domain between the mastectomy and BR groups (Table 3). 
Table 3

Regression coefficients based on Multiple Linear Regression analyses (mixed effects models) of the WHOQOL-BREF and bod

\begin{tabular}{|c|c|c|c|c|c|c|c|c|c|}
\hline & $\begin{array}{l}\text { Age } \\
(\geqslant 55 /<55 Y r)\end{array}$ & $\begin{array}{l}\text { Married/ } \\
\text { cohabited } \\
\text { (Yes/No) }\end{array}$ & $\begin{array}{l}\text { Education } \\
\text { levels } \\
(\geqslant 12 / \\
<12 \text { years })\end{array}$ & 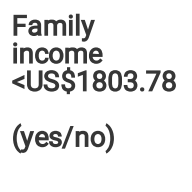 & $\begin{array}{l}\text { Medical } \\
\text { comorbidities } \\
\text { (yes/no) }\end{array}$ & $\begin{array}{l}\text { Chemotherapy: } \\
\leq 6 \text { months } \\
\text { (yes vs No) }\end{array}$ & $\begin{array}{l}\text { Radiotherapy: } \\
\text { Sone year } \\
\text { (yes/no) }\end{array}$ & $\begin{array}{l}\text { Hormone } \\
\text { therapy } \\
\leq \text { one } \\
\text { years (yes } \\
\text { /no) }\end{array}$ & $\begin{array}{l}\text { Lymph } \\
\text { Node } \\
\text { Dissect| } \\
\text { (yes vs }\end{array}$ \\
\hline $\begin{array}{l}\text { WHOQOL } \\
\text { BREF }\end{array}$ & & & & & $-0.17(0.08)$ * & & & & \\
\hline \multicolumn{10}{|l|}{ General QoL } \\
\hline $\begin{array}{l}\text { physical } \\
\text { domain }\end{array}$ & & & & & $-5.60(1.58)^{2}$ & & & & $-8.00((3$ \\
\hline Pain & & & & & $0.19(0.09)^{*}$ & & & & \\
\hline $\begin{array}{l}\text { Medical } \\
\text { dependency }\end{array}$ & & & & & $0.42(0.10)^{1}$ & & & & \\
\hline $\begin{array}{l}\text { Energy \& } \\
\text { fatigue }\end{array}$ & & & & & $-0.23(0.08)^{2}$ & & & & \\
\hline Mobility & $-0.18(0.09)^{*}$ & & & & $-0.25(0.08)^{2}$ & & & & $-0.39(0$. \\
\hline Sleep and rest & & & & & & $-024(0.12)^{*}$ & & & \\
\hline \multicolumn{10}{|l|}{$\begin{array}{l}\text { Daily } \\
\text { Activities }\end{array}$} \\
\hline Work capacity & & & & & $-0.26(0.08)^{2}$ & & & & \\
\hline Psychological & & $4.65(2.23)^{*}$ & & & $-4.29(1.69)^{2}$ & & & & \\
\hline $\begin{array}{l}\text { Positive } \\
\text { feelings }\end{array}$ & & $0.35(0.13)^{2}$ & & & $-0.28(0.10)^{2}$ & & & & \\
\hline Spirituality & & $0.33(0.13)^{*}$ & & & $-0.26(0.10)^{*}$ & & & & \\
\hline Thinking & & & & & $-0.20(0.08)^{*}$ & & & & \\
\hline \multicolumn{10}{|l|}{$\begin{array}{l}\text { Body } \\
\text { appearance }\end{array}$} \\
\hline Self-esteem & & & & & $-0.15(0.07)^{*}$ & & & & \\
\hline $\begin{array}{l}\text { Negative } \\
\text { feelings }\end{array}$ & $-0.21(0.10)^{*}$ & & & & & & & & \\
\hline Social domain & & & $-3.59(1.30)^{2}$ & & & & $3.32(1.48)^{*}$ & & \\
\hline $\begin{array}{l}\text { Personal } \\
\text { relationships }\end{array}$ & & $0.21(0.08)^{*}$ & & & & & & & \\
\hline $\begin{array}{l}\text { Sexual } \\
\text { activity }\end{array}$ & & & $-0.20(0.08)^{*}$ & & & & & $0.18(0.09)^{*}$ & $-0.42(0$. \\
\hline Social support & & & $-0.16(0.05)^{2}$ & & & & $0.17(0.06)^{2}$ & & \\
\hline $\begin{array}{l}\text { Being respect } \\
\text { (SDTW) }\end{array}$ & & $3.78(1.68)^{*}$ & $-3.96(1.22)^{2}$ & & $-2.73(1.26)^{*}$ & & $2.85(1.39)^{*}$ & & \\
\hline Environmental & & $5.73(1.72)^{2}$ & & & $-2.79(1.31)^{*}$ & & & & $-6.35(3$. \\
\hline $\begin{array}{l}\text { Safety, \& } \\
\text { security }\end{array}$ & $0.19(0.09)^{*}$ & & & & & & & & \\
\hline $\begin{array}{l}\text { Physical } \\
\text { environment }\end{array}$ & & $0.58(0.11)^{1}$ & & & $-0.21(0.09)^{*}$ & $-0.21(0.11) *$ & & & \\
\hline $\begin{array}{l}\text { Financial } \\
\text { resources }\end{array}$ & $0.21(0.10)^{*}$ & & & $0.35(0.09)^{1}$ & & & & & \\
\hline Opportunities & & & & $0.20(0.07)^{*}$ & & & $0.16(0.08)^{*}$ & & \\
\hline
\end{tabular}

Significant showing as a $\mathrm{p}^{*}<0.05,{ }^{1}=<0.001,{ }^{2}=<0.01$ and standard errors value under parentheses. All models were controlled for the following confounder income ( $>/<1803.78$ /month) co-morbidities, pathological stage, type of lymph node dissection (sentinel lymph node biopsy $(+/-)$ axillary lymph node dissecti therapy ( $>/<$ one years) and interactions of types of surgeries(mastectomy, modified radical mastectomy and breast reconstruction) WHOQOL-BREF - World $\mathrm{H}$ SDTW- items added in the social domain specific to Taiwan, EDTW- items added in the environmental domain specific to Taiwan 


\begin{tabular}{|c|c|c|c|c|c|c|c|c|c|}
\hline & $\begin{array}{l}\text { Age } \\
(\geqslant 55 /<55 Y r)\end{array}$ & $\begin{array}{l}\text { Married/ } \\
\text { cohabited } \\
\text { (Yes/No) }\end{array}$ & $\begin{array}{l}\text { Education } \\
\text { levels } \\
(\geqslant 12 / \\
<12 \text { years) }\end{array}$ & $\begin{array}{l}\text { Family } \\
\text { income } \\
<\text { <S } \$ 1803.78 \\
\text { (yes } / \text { no) }\end{array}$ & $\begin{array}{l}\text { Medical } \\
\text { comorbidities } \\
\text { (yes/no) }\end{array}$ & $\begin{array}{l}\text { Chemotherapy: } \\
\leq 6 \text { months } \\
\text { (yes vs No) }\end{array}$ & $\begin{array}{l}\text { Radiotherapy: } \\
\text { Sone year } \\
\text { (yes/no) }\end{array}$ & 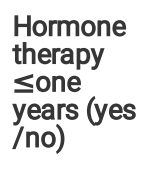 & $\begin{array}{l}\text { Lymph } \\
\text { Node } \\
\text { Dissecti } \\
\text { (yes vs }\end{array}$ \\
\hline $\begin{array}{l}\text { Leisure } \\
\text { activities }\end{array}$ & & $0.30(0.13)^{*}$ & & & $-0.36(0.10)^{2}$ & & $0.26(0.11)^{*}$ & & $-0.71(0$. \\
\hline $\begin{array}{l}\text { Home } \\
\text { environment }\end{array}$ & & $0.17(0.08)^{*}$ & & & & & & & \\
\hline $\begin{array}{l}\text { Access quality } \\
\text { care }\end{array}$ & & & $-0.13(0.06)^{*}$ & & & & & & $-0.39(0$. \\
\hline Transport & & $0.21(0.07)^{2}$ & $-0.11(0.05)^{*}$ & & $-0.13(0.05)^{*}$ & & & & $-0.39(0$. \\
\hline $\begin{array}{l}\text { Eating/food } \\
\text { (EDTW) }\end{array}$ & & $5.36(1.72)^{2}$ & & & $-2.90(1.31)^{*}$ & & & & \\
\hline
\end{tabular}

Significant showing as a $\mathrm{p} *<0.05,{ }^{1}=<0.001,{ }^{2}=<0.01$ and standard errors value under parentheses. All models were controlled for the following confounder income $(>/<1803.78 /$ month) co-morbidities, pathological stage, type of lymph node dissection (sentinel lymph node biopsy $(+/-)$ axillary lymph node dissecti therapy ( $>/<$ one years) and interactions of types of surgeries(mastectomy, modified radical mastectomy and breast reconstruction) WHOQOL-BREF - World $\mathrm{H}$ SDTW- items added in the social domain specific to Taiwan, EDTW-items added in the environmental domain specific to Taiwan

\section{Discussion}

After excluding patients with conservative surgery and control of confounding in the mixed effects models, we found that the BR group had better QoL from one to five years post-surgery, and significant fluctuations were observed after five years' time in terms of QoL compared with the mastectomy and MRM groups. The MRM group showed a stable trend toward low scores in almost all items and domains of WHOQOL as compared with the mastectomy and BR groups. Medical co-morbidities, anxiety/depression status, and BI highly impacted all items and domains of QoL. All these findings would be useful to future patients undergoing BC surgeries and enhancement of the shared decision-making processes that occur among health care teams and patients.

The dynamic changes summarized in Figures 1 and 2 provided additional information for patients received mastectomies and MRM to decide whether BR would be worthwhile for QoL. This result was consistent with a previous study conducted by Wu et al. (2019) in Taiwan on BCS and mastectomy patients within a five year follow-up period. The BCS patients exhibited slightly high QoL fluctuations 30 months post-surgery up to five years post-

surgery [65]. Furthermore, in this study, the QOL curves of women who had BR exhibited an elevated trend in all four domains immediately after surgery until five years post-surgery with wider fluctuations, followed by the mastectomy group and the MRM group, which remained stable with low QoL scores, in that order. This may have been related to surgical site complications or a lack of reimbursement for BR and expiration of catastrophic illness status 5 years after diagnosis in the current scheme of Taiwan's National Health Insurance (NHI)[29, 30, 54].

Furthermore, after controlling for possible confounding factors, no significant relationship in general QoL was found in the women who underwent BR as compared to those undergoing mastectomy and MRM. Similarly, there was a specific interaction between specific post-surgery time points and surgery type on QoL. Women who underwent BR exhibited lower QoL status five years post-surgery compared with the mastectomy and MRM groups in physical domain, social domain, environmental domain, and some items of each domain, but there were no significant influences in the psychological domain on QoL. These results will help policymakers and health care teams determine further comprehensive treatment strategies for BC survivors who received BR beyond five years post-surgery $[11,13]$. However, this is the first study to carry out an analysis of the interaction between time and type of surgery. However, this was a small sample that became even smaller after five years in the BR group. Therefore, future studies should focus on whether BR patients have better QoL after five years post-surgery using repeated measured data to make the results of this study more robust.

The levels of anxiety and depression in women who had undergone BR were comparatively higher than those in the mastectomy and MRM groups five years post-surgery. Also, the "positive feeling" and "body image and appearance" items fluctuated highly with high scores on QoL in the BR group between one to five years post-surgery even their psychological status was not evaluated using a validated questionnaire. As a previous study found that anxiety/ depression among women who had received BR was significantly low one-year post-surgery $[15,48,55]$. Therefore, there is a need to determine the long-term psychological status of women who have undergone BR and a necessity for a long-term plan for QoL in BC survivors also this our study is a such good feasibility.

According to the results in the changes in $\mathrm{Bl}$, the findings indicated that patients who underwent BR experienced many fluctuations and dissatisfaction of their body after one and half years and onwards. This may have been due to high expectations of surgical outcomes of BR after mastectomy or MRMs. Patients could have had difficulty understanding what their post-operative appearance, post operative treatments such as radiotherapy or chemotherapy, and complications might be. However, over time, they may have experienced many changes in their bodies and ended up unhappy with their BI. Furthermore, the mastectomy and MRM patients have a fixed scar in their breast area post-surgery, and may have found that they can had alternatives such as external (prosthesis) $[2,26,53]$ to keep their BI stable and didn't have any worries about further recurrent or post-surgical complications. However, one study examined changes in BI and QoL in women who underwent BCS compared with mastectomies and found similar fluctuation in BI after BCS, but that study did not include BR patients [65]. The type of lymph node dissection has been found to highly influence post-surgical lymphedema in mastectomy and MRM patients, and this may increase dissatisfaction with BI [32, 54, 61, 63]. However, an examination of interaction with post-surgical lymphedema among women undergoing mastectomy, MRM, and BR was not included in this study. 
The results of this study indicated that medical comorbidities, anxiety/depression, and BI highly influence QoL among women who have undergone major BC surgeries. These results appear to have been verified by other studies in Asia and other countries in terms of the key determinants influencing the QoL of women with major breast cancer surgeries from a long-term perspective [6, 16, 29, 39, 47-49, 72]. Additionally, women undergoing BC surgeries who received hormone therapy less than one year post-surgery positively related their long term QoL items to sexual activity due to balancing hormones and expressed gratitude for the ability to mitigate menopausal and vaginal symptoms, increase their BI and self-esteem, maintain their sexual desire, and continue interactive, friendly relationships (in the case of young BC survivors), all of which contribute to their long-term sexual health [20,42]. However, future studies need to assess the relationship between hormone therapy and sexual health from a QoL perspective in more detail.

\section{Strengths and weaknesses}

This study as a few strengths: Firstly, we included more than eight years of repeated measured data to demonstrate dynamic changes in QoL, psychological status, and $\mathrm{BI}$ after major BC surgeries. This will help lead to an understanding of the continued progress being made in surgeries for women with $\mathrm{BC}$ and is important for health care teams to get an overview of QoL outcomes from a long-term perspective that will in turn lead to further development of the healthcare system. Secondly, this is the first study to include BR patients to understand dynamic changes in QoL, psychological status, and BI in this population. It provides insights for health care teams including policymakers to get a clear picture of the timeline as to when and how they need to make effective clinical decisions for patient undergoing BR. Finally, our statistical models provided easy identification of the significant interaction between specific time points and type of surgery on all items and domains of the QoL, as well as anxiety/depression among survivors of BC.

This study has some limitations. First, psychological status (anxiety/depression) data was extracted from anxiety/depression items in the EQ5D questionnaire due to a lack of stored data using a validated anxiety/depression scale in the database at the NCKUH. However, because we did not used anxiety/depression as a post-surgical complication, and our results showed similar with previous studies findings also this did not influence the results for the dynamic changes within given time points[6,39]. However, it is recommended that future studies use valid anxiety and depression scales such as The Beck Depression Inventory (BDI) $[10,48]$ to obtain the long-term psychological status of women undergoing BC surgery. Second, the participants of this study were included only in the Cancer Center database at the NCKUH in Taiwan. To generalize these results, the indices need to be re-assessed using multiple settings, regions, or ethnic groups. Third, this study did not include bilateral breast surgeries, recurrent cancer, and post-surgical complications of mastectomies such as lymphedema or pitting edema due to MRM. Future studies should consider these factors to identify the long-term effects on BI due to mastectomies among BR patients. Finally, we were not able to assess the surgical skills of the health care teams and the cuff size of the bra to add analytical models. These factors most commonly influence body image and psychological status based on QoL, so they should be included in future studies as determinants of BI among patients undergoing and surviving breast cancer surgery. Also, ability of women to cope effectively with their disease was not included in this study; therefore, a phenomenological qualitative study is recommended in the future to compare women who received BR compared with those undergoing mastectomies in a five-year follow-up.

\section{Conclusion}

The most significant determining factors among all items and domains of the QoL were anxiety/depression, medical comorbidities, and BI in patients with breast cancer who received surgery. Those who received BR exhibited a generally better QoL from one to five years post-surgery. However, after five years, significant fluctuations were observed among the women who received BR in terms of QoL compared with the mastectomy and MRM groups. Additionally, the MRM group exhibited stable trends during the follow-up, with a generally lower QoL scores. However, the BR group exhibited high anxiety/depression five years post-surgery compared with the mastectomy and MRM group. The BR groups was dissatisfied with BI after 1.5 years and onward. While all these findings had better to be considered in patient participatory decision making, future studies with a large sample size are warranted for a more definitive recommendation of change of management guidelines.

Applications: These comprehensive study findings will be beneficial to apply to the clinical decision-making process and to provide information for the healthcare team related to when and how they can help improve QoL among women undergoing major BC surgeries, as well as long-term survivors. Future studies need to focus on a qualitative perspective to develop actual scenarios five years post-surgery and beyond involving women with breast cancer, their family members, and their health care teams.

\section{Declarations}

Acknowledgement: I am especially indebted to the National Cheng Kung university to support funding for my studies. Also, those who helped with the English editing of the manuscript.

Funding source: The collection of patient's reported outcome data was supported by serial grants from the Ministry of Science and Technology (MOST 1082627-M-006-001, MOST 109-2621-M-006-007, MOST 110-2627-M-006-010). The funder had no role in the design and conduct of the study; collection, management, analysis, and interpretation of the data; preparation, review, or approval of the manuscript; and decision to submit the manuscript for publication.

Data availability: The database data used and analyzed during the current study are not publicly available due to confidentiality and regulations regarding personal electronic data protection but are available from the corresponding author after approval from the IRB of the National Cheng Kung University Hospital.

Declarations: Conflict of interest: The authors declare that they have no conflicts of interest. 
Ethical approval: This study was approved by The Institutional Review Board of the National Cheng Kung University Hospital before initiation (review No: B-ER110-050).

Informed consent: Informed consent was obtained from every patient before adding the data to the database.

Authorship: Conceptualization: Sriyani padmalatha Konara mudiyanselage, Nai-Ying Ko Jung-Der Wang, Su-Ying Fang, Methodology: Sriyani padmalatha Konara mudiyanselage, Nai-Ying Ko Jung-Der Wang, Su-Ying Fang, Formal analysis and investigation: Sriyani padmalatha Konara mudiyanselage, Yi-Lin Wu, Chen Chang Chun, Shikha Kukreti, Chia-Ni Lin Writing - original draft preparation: Sriyani padmalatha Konara mudiyanselage, Writing - review and editing: Han-Chang Ku ,Yi-Tseng Tsai, Shikha Kukreti, Nai-Ying Ko Jung-Der Wang, Su-Ying Fang, Funding acquisition: Sriyani padmalatha Konara mudiyanselage, Nai-Ying Ko, Jung-Der Wang, Resources: Sriyani padmalatha Konara mudiyanselage, Nai-Ying Ko, Supervision: Nai-Ying Ko, Jung-Der Wang, Su-Ying Fang.

Informed consent: Informed consent was obtained from every patient before adding the data to the database.

\section{References}

1. Ahern TP, Lash TL, Thwin SS, Silliman RA (2009) Impact of acquired comorbidities on all-cause mortality rates among older breast cancer survivors. Medical care 47:73. doi: https://doi.org/10.1097/MLR.0b013e318180913c

2. Anishya A, Appavu S (2021) External breast prosthesis for post mastectomy women. Asian Journal of Nursing Education and Research 11:427-430. doi: https://doi.org/10.52711/2349-2996.2021.00103

3. Archangelo SdCV, Sabino Neto M, Veiga DF, Garcia EB, Ferreira LM (2019) Sexuality, depression and body image after breast reconstruction. Clinics 74 . doi: https://doi.org/10.6061/clinics/2019/e883

4. Bland KI, Chang HR, Copeland III EM (2018) Modified radical mastectomy and simple mastectomy. In: The Breast. Elsevier, p 443-461. e443

5. Campbell-Enns HJ, Woodgate RL (2017) The psychosocial experiences of women with breast cancer across the lifespan: a systematic review. Psychooncology 26:1711-1721. doi: https://doi.org/10.1002/pon.4281

6. Chang Y-C, Yao G, Hu SC, Wang J-D (2015) Depression affects the scores of all facets of the WHOQOL-BREF and may mediate the effects of physical disability among community-dwelling older adults. PloS one 10:e0128356. doi: https://doi.org/10.1371/journal.pone.0128356

7. Chen W-L, Chen Y-Y, Wu W-T, Ho C-L, Wang C-C (2021) Life expectancy estimations and determinants of return to work among cancer survivors over a 7year period. Scientific Reports 11:1-12. doi: https://doi.org/10.1038/s41598-021-92306-9

8. Chetrit A, Ben-Avraham S, Mandelzweig L, Amitai T, Danieli NS, Silverman B, Sadetzki S (2021) Breast cancer survivors: physical and mental quality of life 10 years following diagnosis, a case-control study. Breast Cancer Research and Treatment:1-10. doi: https://doi.org/10.1007/s10549-021-06156-0

9. Claessens AK, Ramaekers BL, Lobbezoo DJ, van Kampen RJ, de Boer M, van de Wouw AJ, Dercksen MW, Geurts SM, Joore MA, Tjan-Heijnen VC (2020) Quality of life in a real-world cohort of advanced breast cancer patients: a study of the SONABRE Registry. Quality of Life Research 29:3363-3374. doi: https://doi.org/10.1007/s11136-020-02604-4

10. Colomo N, Olveira C, Hernández-Pedrosa J, Bergero T, Fábrega-Ruz J, Porras N, Girón MV, de Rota LF, Olveira G (2021) Validity of self-rating screening scales for the diagnosis of depression and anxiety in adult patients with bronchiectasis. Archivos de Bronconeumología (English Edition) 57:179-185. doi: https://doi.org/10.1016/j.arbr.2020.01.012

11. Coombes RC, Tovey H, Kilburn L, Mansi J, Palmieri C, Bartlett J, Hicks J, Makris A, Evans A, Loibl S (2021) Effect of Celecoxib vs Placebo as Adjuvant Therapy on Disease-Free Survival Among Patients With Breast Cancer: The REACT Randomized Clinical Trial. JAMA oncology 7:1291-1301. doi:

https://doi.org/10.1002/cam4.3979

12. Dauplat J, Kwiatkowski F, Rouanet P, Delay E, Clough K, Verhaeghe J, Raoust I, Houvenaeghel G, Lemasurier P, Thivat E (2017) Quality of life after mastectomy with or without immediate breast reconstruction. Journal of British Surgery 104:1197-1206. doi: https://doi.org/10.1002/bjs.10537

13. de Boniface J, Szulkin R, Johansson AL (2021) Survival After Breast Conservation vs Mastectomy Adjusted for Comorbidity and Socioeconomic Status: A Swedish National 6-Year Follow-up of 48986 Women. JAMA surgery. doi: https://doi.org/10.1001/jamasurg.2021.1438

14. Doherty C, Pearce S, Baxter N, Knowles S, Ross D, McClure JA, Brackstone M (2020) Trends in immediate breast reconstruction and radiation after mastectomy: A population study. The Breast Journal 26:446-453. doi: https://doi.org/10.1111/tbj.13500

15. Domenici L, Caputo GG, Losco L, Di Taranto G, Lo Torto F, Pierazzi DM, Governa M, Benedetti Panici P, Ribuffo D, Cigna E (2021) Muscle-Sparing SkinReducing Breast Reconstruction with Pre-Pectoral Implants in Breast Cancer Patients: Long-Term Assessment of Patients' Satisfaction and Quality of Life. Journal of Investigative Surgery:1-7. doi: https://doi.org/10.1080/08941939.2021.1923874

16. El Haidari R, Abbas LA, Nerich V, Anota A (2020) Factors associated with health-related quality of life in women with breast cancer in the Middle East: a systematic review. Cancers 12:696. doi: https://doi.org/10.3390/cancers12030696 
17. Eltahir Y, Werners LL, Dreise MM, van Emmichoven IAZ, Jansen L, Werker PM, de Bock GH (2013) Quality-of-life outcomes between mastectomy alone and breast reconstruction: comparison of patient-reported BREAST-Q and other health-related quality-of-life measures. Plastic and reconstructive surgery 132:201e-209e. doi: https://doi.org/10.1097/PRS.0b013e31829586a7

18. Fanakidou I, Zyga S, Alikari V, Tsironi M, Stathoulis J, Theofilou P (2018) Mental health, loneliness, and illness perception outcomes in quality of life among young breast cancer patients after mastectomy: the role of breast reconstruction. Quality of Life Research 27:539-543. doi: https://doi.org/10.1007/s11136-017-1735-x

19. Fang S-Y, Chang H-T, Shu B-C (2014) Objectified body consciousness, body image discomfort, and depressive symptoms among breast cancer survivors in Taiwan. Psychology of Women Quarterly 38:563-574. doi: https://doi.org/10.1177/0361684314552652

20. Franzoi MA, Agostinetto E, Perachino M, Del Mastro L, de Azambuja E, Vaz-Luis I, Partridge AH, Lambertini M (2021) Evidence-based approaches for the management of side-effects of adjuvant endocrine therapy in patients with breast cancer. The Lancet Oncology. doi: https://doi.org/10.1016/S14702045(20)30666-5

21. Gonzalez L, Bardach A, Palacios A, Peckaitis C, Ciapponi A, Pichón-Riviere A, Augustovski F (2021) Health-Related Quality of Life in Patients with Breast Cancer in Latin America and the Caribbean: A Systematic Review and Meta-Analysis. The oncologist 26:e794-e806. doi: https://doi.org/10.1002/onco.13709

22. Gradishar WJ, Anderson BO, Balassanian R, Blair SL, Burstein HJ, Cyr A, Elias AD, Farrar WB, Forero A, Giordano SH (2018) Breast cancer, version 4.2017, NCCN clinical practice guidelines in oncology. Journal of the National Comprehensive Cancer Network 16:310-320. doi: https://doi.org/10.6004/jnccn.2018.0012

23. Group W (1998) Development of the World Health Organization WHOQOL-BREF quality of life assessment. Psychological medicine 28:551-558. doi: https://doi.org/10.1017/S0033291798006667

24. Group W (1995) The World Health Organization quality of life assessment (WHOQOL): position paper from the World Health Organization. Social science \& medicine 41:1403-1409. doi: https://doi.org/10.1016/0277-9536(95)00112-K

25. Ho PJ, Gernaat SA, Hartman M, Verkooijen HM (2018) Health-related quality of life in Asian patients with breast cancer: a systematic review. BMJ open 8:e020512. doi: http://dx.doi.org/10.1136/bmjopen-2017-020512

26. Hojan K (2020) Does the weight of an external breast prosthesis play an important role for women who undergone mastectomy? Reports of Practical Oncology and Radiotherapy 25:574-578. doi: https://doi.org/10.1016/j.rpor.2020.04.015

27. Honkanen N, Mustonen L, Kalso E, Meretoja T, Harno H (2021) Breast reconstruction after breast cancer surgery-persistent pain and quality of life 1-8 years after breast reconstruction. Scandinavian Journal of Pain. doi: https://doi.org/10.1515/sjpain-2021-0026

28. Hopwood P, Fletcher I, Lee A, Al Ghazal S (2001) A body image scale for use with cancer patients. European journal of cancer 37:189-197.

29. Huang C-C, Lien H-H, Tu S-H, Huang C-S, Jeng J-Y, Chao H-L, Sun H-L, Chie W-C (2010) Quality of life in Taiwanese breast cancer survivors with breastconserving therapy. Journal of the Formosan Medical Association 109:493-502. doi: https://doi.org/10.1016/S0929-6646(10)60083-6

30. Hung YN, Liu TW, Wen FH, Chou WC, Tang ST (2017) Escalating Health Care Expenditures in Cancer Decedents' Last Year of Life: A Decade of Evidence from a Retrospective Population-Based Cohort Study in Taiwan. The oncologist 22:460. doi: https://doi.org/10.1634/theoncologist.2016-0283

31. Hwang J-S, Wang J-D (2004) Integrating health profile with survival for quality of life assessment. Quality of Life Research 13:1-10. doi: https://doi.org/10.1023/B:QURE.0000015299.45623.38

32. Jørgensen MG, Toyserkani NM, Hansen FG, Bygum A, Sørensen JA (2021) The impact of lymphedema on health-related quality of life up to 10 years after breast cancer treatment. NPJ breast cancer 7:1-8. doi: https://doi.org/10.1038/s41523-021-00276-y

33. Kao Y-L, Ou C-H, Lin S-H, Chang S-M, Wang J-D, Tsai Y-S (2021) Dynamic Changes of Generic Quality of Life after Different Treatments for Localized Prostate Cancer. Journal of Clinical Medicine 10:158. doi: https://doi.org/10.3390/jcm10010158

34. Lavdaniti M, Owens DA, Liamopoulou P, Marmara K, Zioga E, Mantzanas MS, Evangelidou E, Vlachou E (2019) Factors influencing quality of life in breast cancer patients six months after the completion of chemotherapy. Diseases 7:26. doi: https://doi.org/10.3390/diseases7010026

35. Lee H-Y, Hung M-C, Hu F-C, Chang Y-Y, Hsieh C-L, Wang J-D (2013) Estimating quality weights for EQ-5D (EuroQol-5 dimensions) health states with the time trade-off method in Taiwan. Journal of the Formosan Medical Association 112:699-706. doi: https://doi.org/10.1016/j.jfma.2012.12.015

36. Lei S, Zheng R, Zhang S, Wang S, Chen R, Sun K, Zeng H, Zhou J, Wei W (2021) Global patterns of breast cancer incidence and mortality: A populationbased cancer registry data analysis from 2000 to 2020. Cancer Communications. doi: https://doi.org/10.1002/cac2.12207

37. Li R, Daniel R, Rachet B (2016) How much do tumor stage and treatment explain socioeconomic inequalities in breast cancer survival? Applying causal mediation analysis to population-based data. European journal of epidemiology 31:603-611. doi: https://doi.org/10.1007/s10654-016-0155-5 
38. Lin C-Y, Hwang J-S, Wang W-C, Lai W-W, Su W-C, Wu T-Y, Yao G, Wang J-D (2019) Psychometric evaluation of the WHOQOL-BREF, Taiwan version, across five kinds of Taiwanese cancer survivors: Rasch analysis and confirmatory factor analysis. Journal of the Formosan Medical Association 118:215-222. doi: https://doi.org/10.1016/j.jfma.2018.03.018

39. Lu I-C, Jean M-CY, Lei S-M, Cheng H-H, Wang J-D (2011) BSRS-5 (5-item Brief Symptom Rating Scale) scores affect every aspect of quality of life measured by WHOQOL-BREF in healthy workers. Quality of Life Research 20:1469-1475. doi: https://doi.org/10.1007/s11136-011-9889-4

40. Maguire G, Lee E, Bevington D, Küchemann C, Crabtree R, Cornell C (1978) Psychiatric problems in the first year after mastectomy. Br med J 1:963-965. doi: https://doi.org/10.1136/bmj.1.6118.963

41. Marinkovic M, Djordjevic N, Djordjevic L, Ignjatovic N, Djordjevic M, Karanikolic V (2021) Assessment of the quality of life in breast cancer depending on the surgical treatment. Supportive Care in Cancer 29:3257-3266. doi: https://doi.org/10.1007/s00520-020-05838-7

42. Marsh S, Borges VF, Coons HL, Afghahi A (2020) Sexual health after a breast cancer diagnosis in young women: clinical implications for patients and providers. Breast Cancer Research and Treatment:1-9. doi: https://doi.org/10.1007/s10549-020-05880-3

43. Mazo C, Kearns C, Mooney C, Gallagher WM (2020) Clinical decision support systems in breast cancer: A systematic review. Cancers 12:369. doi: https://doi.org/10.3390/cancers12020369

44. Miller AM, Steiner CA, Barrett ML, Fingar KR, Elixhauser A (2017) Breast reconstruction surgery for mastectomy in hospital inpatient and ambulatory settings, 2009-2014: statistical brief\# 228. In: Healthcare Cost and Utilization Project (HCUP) Statistical Briefs (Rockville, MD: Agency for Healthcare Research and Quality (US)). p 1-28

45. Moradzadeh R, Mansournia MA, Baghfalaki T, Ghiasvand R, Noori-Daloii MR, Holakouie-Naieni K (2016) Misclassification adjustment of family history of breast cancer in a case-control study: a Bayesian approach. Asian Pacific Journal of Cancer Prevention 16:8221-8226. doi:

https://doi.org/10.7314/APJCP.2015.16.18.8221

46. Moshina N, Falk R, Hofvind S (2021) Long-term quality of life among breast cancer survivors eligible for screening at diagnosis: a systematic review and meta-analysis. Public Health 199:65-76. doi: https://doi.org/10.1016/j.puhe.2021.08.008

47. Okati-Aliabad H, Ansari-Moghadam A, Mohammadi M, Kargar S, Shahraki-Sanavi F (2021) The prevalence of anxiety and depression and its association with coping strategies, supportive care needs, and social support among women with breast cancer. Supportive Care in Cancer:1-8. doi: https://doi.org/10.1007/s00520-021-06477-2

48. Padmalatha S, Tsai Y-T, Ku H-C, Wu Y-L, Yu T, Fang S-Y, Ko N-Y (2021) Higher Risk of Depression After Total Mastectomy Versus Breast Reconstruction Among Adult Women With Breast Cancer: A Systematic Review and Metaregression. Clinical breast cancer. doi: https://doi.org/10.1016/j.clbc.2021.01.003

49. Park J, Rodriguez JL, O'Brien KM, Nichols HB, Hodgson ME, Weinberg CR, Sandler DP (2021) Health-related quality of life outcomes among breast cancer survivors. Cancer 127:1114-1125. doi: https://doi.org/10.1002/cncr.33348

50. Pickard AS, Ray S, Ganguli A, Cella D (2012) Comparison of FACT- and EQ-5D-Based Utility Scores in Cancer. Value in Health 15:305-311. doi: https://doi.org/10.1016/j.jval.2011.11.029

51. Pirnia B, Homayounfar N, Hosseini N, Ebrahimi F, Haj Sadeghi Z, Malekanmehr P (2020) The predictive role of body image and sexual function in quality of life after modified radical mastectomy regarding the mediating role of emotion; a cross sectional study. International Journal of Cancer Management 13. doi: https://doi.org/10.5812/ijcm.101371

52. Politi MC, Lee CN, Philpott-Streiff SE, Foraker RE, Olsen MA, Merrill C, Tao Y, Myckatyn TM (2020) A randomized controlled trial evaluating the BREASTChoice tool for personalized decision support about breast reconstruction after mastectomy. Annals of surgery 271:230-237. doi: https://doi.org/10.1097/SLA.0000000000003444

53. Qiu J, Hou S, Li P, Huang L (2021) Medical professionals' knowledge of the use of external breast prostheses among breast cancer patients in China-a cross-sectional study. Gland Surgery 10:595. doi: https://doi.org/10.21037/gs-20-657

54. Siegel EL, Whiting J, Kim Y, Sun W, Laronga C, Lee MC (2021) Effect of surgical complications on outcomes in breast cancer patients treated with mastectomy and immediate reconstruction. Breast Cancer Research and Treatment:1-8. doi: https://doi.org/10.1007/s10549-021-06241-4

55. Siqueira HFF, de Almeida Teixeira JL, da Silva Lessa Filho R, Hora EC, Brasileiro FF, de Souza Borges K, Brito ÉdAC, Lima MS, Marques AD, Moura AR (2020) Patient satisfaction and quality of life in breast reconstruction: assessment of outcomes of immediate, delayed, and nonreconstruction. BMC research notes 13:1-7. doi: https://doi.org/10.1186/s13104-020-05058-6

56. Słowik AJ, Jabłoński MJ, Michałowska-Kaczmarczyk AM, Jach R (2017) Evaluation of quality of life in women with breast cancer, with particular emphasis on sexual satisfaction, future perspectives and body image, depending on the method of surgery. Psychiatr Pol 51:871-888. doi:

http://dx.doi.org/10.12740 
57. Society AC (2019) Breast cancer facts \& figures 2019-2020. Am. Cancer Soc:1-44. doi: https://www.cancer.org/content/dam/cancer$\mathrm{org} /$ research/cancer-facts-and-statistics/breast-cancer-facts-and-figures/breast-cancer-facts-and-figures-2019-2020.pdf

58. Spatuzzi R, Vespa A, Lorenzi P, Miccinesi G, Ricciuti M, Cifarelli W, Susi M, Fabrizio T, Ferrari MG, Ottaviani M (2016) Evaluation of social support, quality of life, and body image in women with breast cancer. Breast Care 11:28-32. doi: https://doi.org/10.1159/000443493

59. Sung H, Ferlay J, Siegel RL, Laversanne M, Soerjomataram I, Jemal A, Bray F (2021) Global cancer statistics 2020: GLOBOCAN estimates of incidence and mortality worldwide for 36 cancers in 185 countries. CA: a cancer journal for clinicians 71:209-249. doi: https://doi.org/10.3322/caac.21660

60. Tachi T, Teramachi H, Tanaka K, Asano S, Osawa T, Kawashima A, Yasuda M, Mizui T, Nakada T, Noguchi Y (2015) The impact of outpatient chemotherapy-related adverse events on the quality of life of breast cancer patients. PLoS One 10:e0124169. doi: https://doi.org/10.1371/journal.pone.0124169

61. Taghian NR, Miller CL, Jammallo LS, O’Toole J, Skolny MN (2014) Lymphedema following breast cancer treatment and impact on quality of life: a review. Critical reviews in oncology/hematology 92:227-234. doi: https://doi.org/10.1016/j.critrevonc.2014.06.004

62. Thorarinsson A, Fröjd V, Kölby L, Ljungdal J, Taft C, Mark H (2017) Long-term health-related quality of life after breast reconstruction: comparing 4 different methods of reconstruction. Plastic and reconstructive surgery Global open 5. doi: https://doi.org/10.1097/G0X.0000000000001316

63. Togawa K, Ma H, Smith AW, Neuhouser ML, George SM, Baumgartner KB, McTiernan A, Baumgartner R, Ballard RM, Bernstein L (2021) Self-reported symptoms of arm lymphedema and health-related quality of life among female breast cancer survivors. Scientific reports 11:1-13. doi:

https://doi.org/10.1038/s41598-021-89055-0

64. Tsai H-Y, Kuo RN-C, Chung K-p (2017) Quality of life of breast cancer survivors following breast-conserving therapy versus mastectomy: a multicenter study in Taiwan. Japanese journal of clinical oncology 47:909-918. doi: https://doi.org/10.1093/jjco/hyx099

65. Wu T-Y, Chang T-W, Chang S-M, Lin Y-Y, Wang J-D, Kuo Y-L (2019) Dynamic Changes Of Body Image And Quality Of Life In Breast Cancer Patients. Cancer Management and Research 11:10563. doi: https://doi.org/10.2147/CMAR.S223314

66. Wu TY, Chung CH, Lin CN, Hwang JS, Wang JD (2018) Lifetime risks, loss of life expectancy, and health care expenditures for 19 types of cancer in Taiwan. Clin Epidemiol 10:581-591. doi: https://doi.org/10.2147/CLEP.S155601

67. Yang S-C, Kuo C-W, Lai W-W, Lin C-C, Su W-C, Chang S-M, Wang J-D (2019) Dynamic Changes of Health Utility in Lung Cancer Patients Receiving Different Treatments: A 7-Year Follow-up. Journal of Thoracic Oncology 14:1892-1900. doi: https://doi.org/10.1016/j.jtho.2019.07.007

68. Yang S-C, Lin C-C, Lai W-W, Chang S-M, Hwang J-S, Su W-C, Wang J-D (2018) Dynamic changes in quality of life after three first-line therapies for EGFR mutation-positive advanced non-small-cell lung cancer. Therapeutic advances in medical oncology 10:1758834018755072. doi:

https://doi.org/10.1177/1758834018755072

69. Yao G, Chung C-W, Yu C-F, Wang J-D (2002) Development and verification of validity and reliability of the WHOQOL-BREF Taiwan version. Journal of the Formosan Medical Association 101:342-351.

70. Yao G, Wu C-h (2005) Factorial invariance of the WHOQOL-BREF among disease groups. Quality of Life Research 14:1881-1888. doi: https://doi.org/10.1007/s11136-005-3867-7

71. Zhang Q, Zhao H, Zheng Y (2019) Effectiveness of mindfulness-based stress reduction (MBSR) on symptom variables and health-related quality of life in breast cancer patients-a systematic review and meta-analysis. Supportive Care in Cancer 27:771-781. doi: https://doi.org/10.1007/s00520-018-4570-x

72. Zhou K, Wang W, Li M, An J, Huo L, He X, Li J, Li X (2020) Body image mediates the relationship between post-surgery needs and health-related quality of life among women with breast cancer: a cross-sectional study. Health and Quality of Life Outcomes 18:1-11. doi: https://doi.org/10.1186/s12955-02001400-5

\section{Figures}



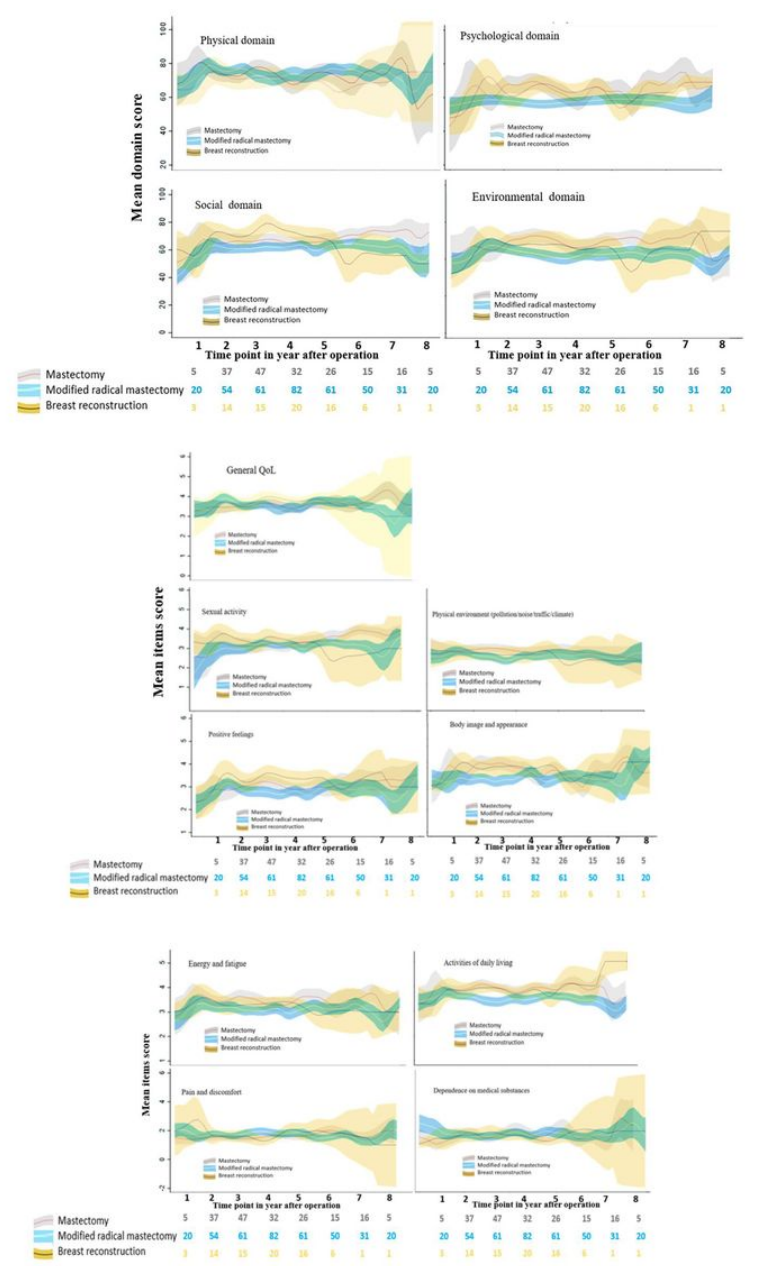

\section{Figure 1}

Dynamic changes of the quality-of-life score in four domains and selected items score among patients with mastectomies, modified radical mastectomy (MRM), and breast reconstruction (BR). The shaded area in the graph shows a 95\% confidence interval (Cl) for each domain/item score. 


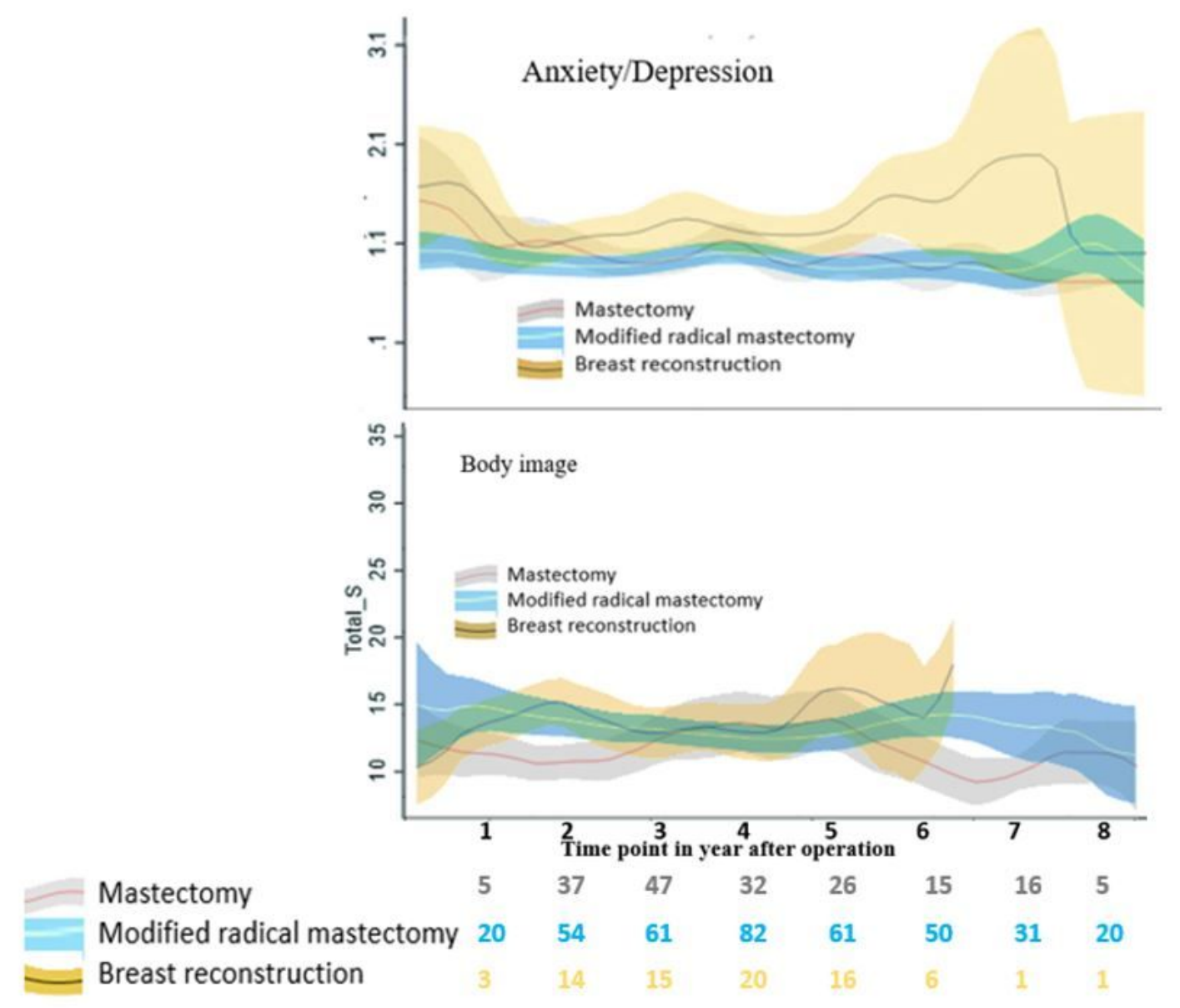

Figure 2

Dynamic changes of the quality-of-life in anxiety/depression of EQ5D scale and body image on BIS scale among patients with mastectomies, modified radical mastectomy (MRM), and breast reconstruction (BR). The shaded area in the graph shows a 95\% confidence interval (Cl) for each domain/item score.

\section{Supplementary Files}

This is a list of supplementary files associated with this preprint. Click to download.

- SupplementaryFigureandTable.docx 